\title{
Osteometric Studies on Human Femurs
}

\author{
T.Jayachandra Pillai ${ }^{1}$, C.K.lakshmi Devi ${ }^{2}$, T.Sobha Devi ${ }^{3}$ \\ ${ }^{I}$ Proffessor, Dept of Anatomy, S.V. Medical College, Tirupati NTRUHS India. \\ ${ }^{2}$ Associate proffessor, Dept of Anatomy, S.V. Medical College, Tirupati NTRUHS India. \\ ${ }^{3}$ Assistant proffessor, Dept of Anatomy, S.V. Medical College, Tirupati NTRUHS India.
}

\begin{abstract}
It is commonly accepted that the examination and statistical analysis of femoral Anthropometry among different populations reveals a great amount of variation due to the face that the femoral Anthropometry measurements from different countries are likely to be affected by racial variations in diet, heredity, climate and other geographical factors related to life. Anatomists have carried out various measurements to differentiate sex of the femora. This was done in femora of either known or unknown sex. Various parameters were used by Anatomists for measuring femora. 50 dry human femora of unknown sex were collected from different medical institution and Anthropology department of S. V. University, Tirupati. By eliminating pathologicaly misfit femora, 50 femora in good condition were selected. Each femur was carefully measured for 6 parameters which are already described in materials and methods. 1.Maximum length of femur,2.Vertical diameter of head,3.Epicondylar breadth,4.Neck-shaft angle,5.Transverse diameter of head,6.AP diameter of shaft Upper,middle, lower.The measurements were statistically analyzed and tabulated. The present study reveals that femora of unknown gender can be sexed to the extend of 75-80\% by three parameters namely, Vertical diameter of head, Neck-shaft angle and Transverse diameter of head.
\end{abstract}

Key words:Femur, Maximum length of femur,Vertical diameter of head,Epicondylarbreadth,Neck-shaft angle,Transverse diameter of head,AP diameter of shaft

\section{Introduction}

Skeleton is playing important role in various sciences like medicine, forensic sciences, Anthropology etc., Estimation of sex, age, race, stature by skeleton and the presence of disease is discovered by Krogman and Iscan(Ref.7) (1986). They stated that record of organic evolution is largely written by the hard parts of the body recognizable even after many years of death. Sex is determined after death by skeletal remains of that individual by some Forensic Anthropologists with the help of pelvis, skull. It is some what easier to identify the sex of individual. Here in the present study we are taking the long bones (Femur) either individually or in combination, have been subjected to statistical and morphological analysis for the purpose of determination of sex.

Studies on Femur has been reported on various populations and there are many variations in size in different populations and Germans (Mall et al.2000, Ref.9).It is commonly accepted that the examination and statistical analysis of femoral Anthropometry among different populations reveals a great amount of variation due to the face that the femoral Anthropometry measurements from different countries are likely to be affected by racial variations in diet, heredity, climate and other geographical factors related to life style.Anatomists have carried out various measurements to differentiate sex of the femora. This was done in femora of either known or unknown sex. Various parameters were used by Anatomists for measuring femora.

The femur is ossified from one primary centre for the shaft, 3 secondary centre for upper end, one each for head, greater trochanter and lesser trochanter and one secondary centre for lower end.The primary centre appears in the middle of the shaft at about $7^{\text {th }}$ week of intrauterine life. The centre for the head appears at about $6^{\text {th }}$ month to 1 year after birth, that for the greater trochanter about $4^{\text {th }}$ year, and for lesser trochanter at about $14^{\text {th }}$ year. The lesser trochanter unites with diaphysis during $16^{\text {th }}$ year, the greater trochanter unites with diaphysis during 16the year, the greater trochanter at $17^{\text {th }}$ year and the head at about $18^{\text {th }}$ year. The neck is derived from the primary centre as a extension of shaft. The epiphyseal plate between the head and neck is initially horizontal and becomes oblique by the age of 8 to 12 years. Therefore, the lower end is growing end of femur.The head and lower end are pressure epiphyses, where as the greater and lesser trochanters are traction epiphyses.

\section{Material:}

\section{Materials \& Methods}

The material used for the study contained 50 human femora of unkown sex obtained from different medical institutions and Anthropology department of S. V. University, Tirupati town and from the departmental pool. The bones collected are free from any pathological lesions or fractures and are in good condition. The bones collected roughly belong to the age group of 18 to 60 years. 


\section{Instruments Used:}

1. metal sliding caliper

2. Osteometric Board

\section{Method of Study}

The following parameters were taken into consideration and measured on femur in order to determine the sex.

1. Maximum length

2. Vertical diameter of head

3. Epi-condylar breadth

4. Neck-shaft angle

5. Transverse diameter of head

6. AP diameter of shaft - Upper,Middle,Lower

1. Maximum Length:It measures the straight distance between the highest point of the head and the deepest point on the medial condyle(Fig.1).

2. Vertical diameter of Head:It measures the straight distance between the highest and deepest points of the head(Fig.2).

3. EpicondylarBreadth:It measures the distance between the most projected points on the epicondyles(Fig.3).

Procedure: Place the bone in such a manner on the osteometric board with its posterior surface downwards, that one of the epicondyles touches the vertical long wall while the movable cross piece touches the other lateral condyle.

4. Neck-Shaft Angle:It is the angle made by axis of shaft with the axis of the upper anterior collum. Axis of collum is determined by means of a thread which divides the anterior surface of tecollum in two equal halves. Axis of the Shaft is determined by a thread which extends in the mid sagittal plane over the anterior surface of the bone from the upper end of the oblique line of the ondyles. In case of strongly developed torsion, it may be difficult to fix a thread on the entire surface; so take only the axis of the upper shaft into consideration for such cases(Fig.4).

Materials: Thread, mud clay

5. Transverse diameter of head:It measures the straight distance between the most laterally projected points on the equatorial plane taken at right angle to the vertical diameter(Fig.5)

6. Antero-posterior diameter of shaft:Upper : It measures the antero-posterior diameter of the upper shaft taken at right angle to the transverse diameter of shaft.Middle : It measures the distance between the anterior and posterior surfaces of the bone approximately at the middle of the shaft ie., the highest elevation of the lineaaspera.Lower : It measures the minimum distance between the anterior-posterior margins of the lower part of the shaft, approximately $4 \mathrm{~cm}$ above the cartilaginous margin of the condyles taken in the mid sagittal plane.

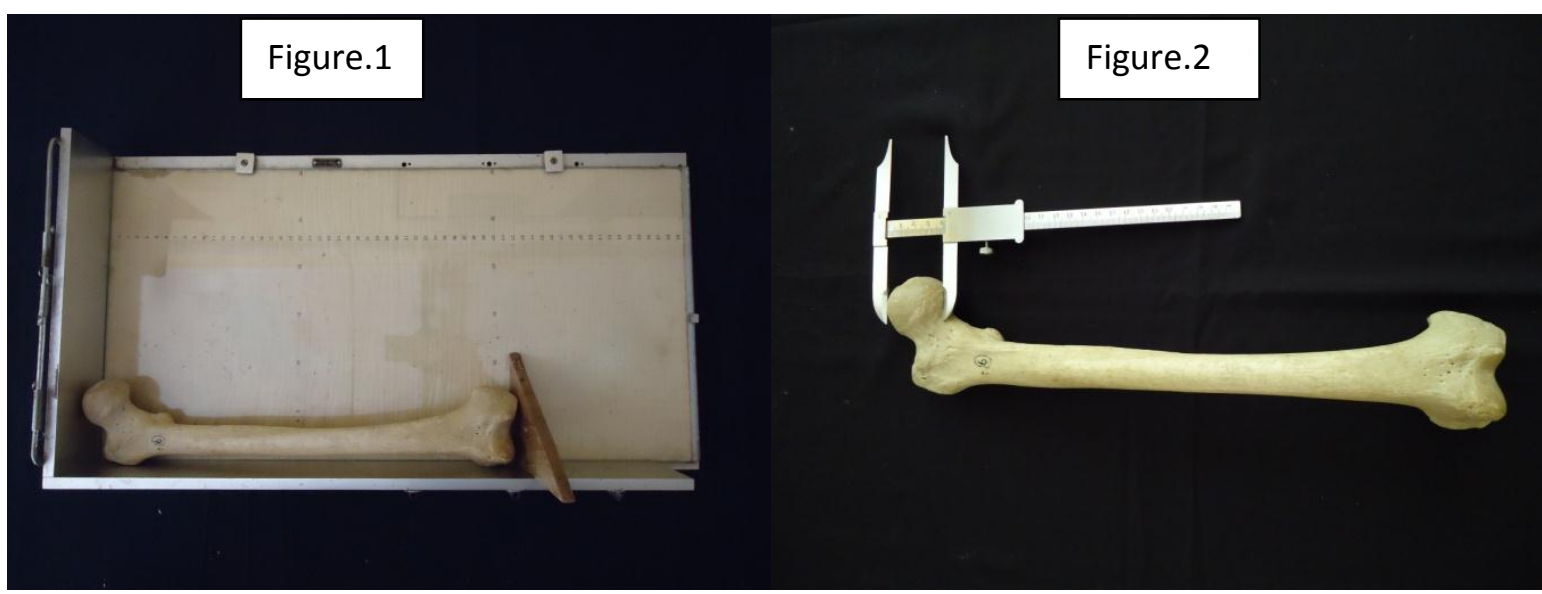



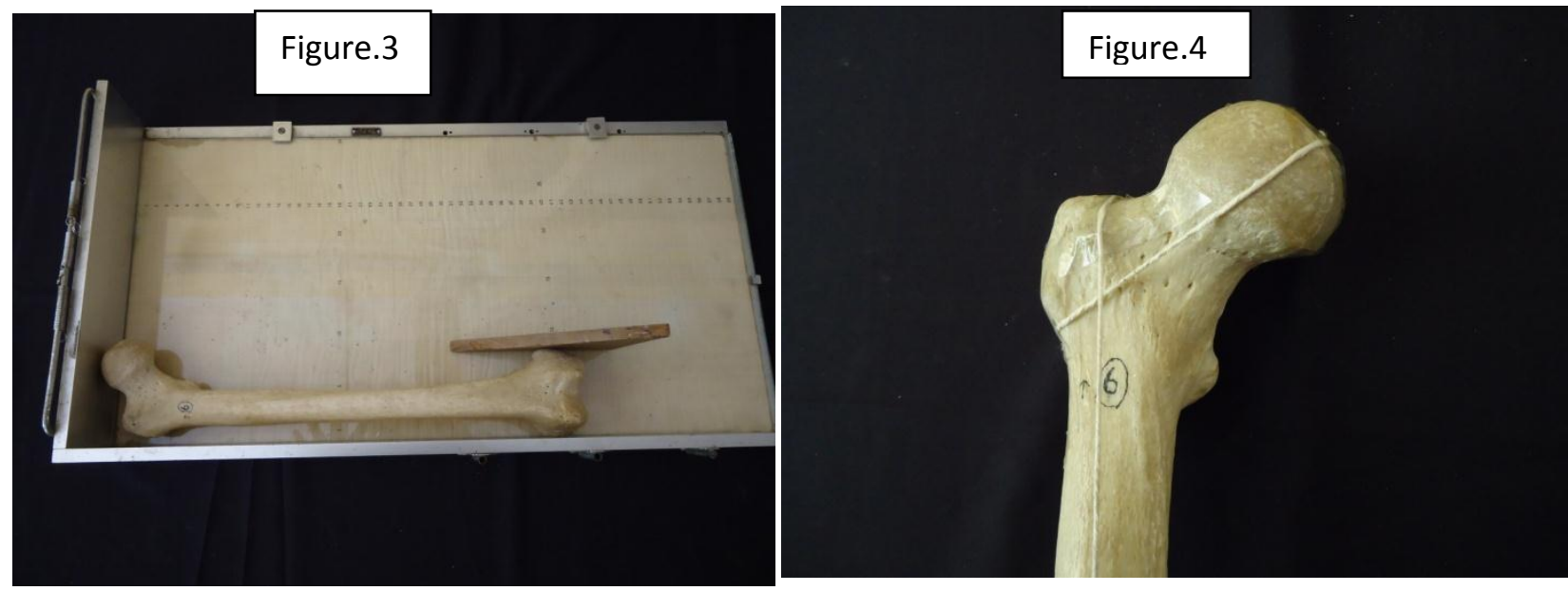

III. Results And Discussion

50 dry human femora of unknown sex were collected from different medical institutions and Anthropology department of S.V. University, Tirupati. By eliminating pathologically misfit femora, 50 femora in good condition were selected. Each femur was carefully measured for 6 parameters which were already described in materials and methods. The data thus obtained is tabulated (table - 1). An attempt is made to identify the femora of either sex by measuring various parameters and by comparing the data with the available previous values.

The maximum length of the femur varies from a minimum of $373 \mathrm{~mm}$ to maximum of $514 \mathrm{~mm}$ with a mean value of $437.4 \mathrm{~mm}$ (table 2). When this is compared to the range of the known sex, 42 femora out 50 could be identified as belonging to male and 8 to female (table 5). Maximum length of femur has been reported earlier ( Leelavathy N, et al. 2000, Ref.8). Comparisons were drawn separately for male left and right femora as well as for female left and right femora, because individuals tend to favour one limb over other. It also has been observed that the female femur is shorter than male and in male the left longer than right and vice versa in female. Maximum length of femur" was the best parameter for sexing the unknown femora (Leelavathy et al.2000,Ref.8). . Discriminant analysis confirmed that the male femur is usually larger than the female femur (Alan M. W Porter 1994,Ref.1) sex differences in long bones is that typically male bones are longer and more massive than typically female bones (krogman 55,Ref.16). In my present study there is wide variation of this particular parameter.

Vertical diameter of head of femur ranges from a minimum $34 \mathrm{~mm}$ to maximum $51 \mathrm{~mm}$ with a mean value of $42.24 \mathrm{~mm}$ (table 2). When compared to the range of known sex, 23 out of 50 identified as belonging to male and 27 to female (table 5). This is in correlation with the present observation and this parameter is giving higher percentage of accuracy in sexing the femur.The mean head diameter of male femur was significantly greater than the mean head diameter of female femur (S.A Asala 2000,Ref.1). "Max-head diameter alone could correctly assign sex to $92.5 \%$ of males and 95.5\% females" (Rumapurkait 2004,Ref.11). Head vertical diameter of Right femur was significantly greater than Left femur.

In 1913-14 and 1914-15, Parsons suggested width of lower end as sex category and stated that $>72 \mathrm{~mm}$ is male and $<71 \mathrm{~mm}$ is female, $71-72 \mathrm{~mm}$ is male or female. Neck-shaft angle ranges from a minimum of $106^{\circ}$ to maxium of $135^{\circ}$ with a mean value of $125.30^{\circ}$ (table 2) when this was compared with the range of known sex 24 femora out of 50 could be identified as belonging to male and 26 to female. This is in correlation with the present observation and this parameter is giving higher $\%$ of accuracy (table 5) in sexing of the femur. Neckshaft angle has been reported earlier (W. Henry Hollinshead 1966,Ref.5,6) with an average of $126^{\circ}$. The neck shaft angle ranges from $120^{\circ}-136^{\circ}$ with a mean of $126.7^{\circ}$. Any estimated defective angle can be of help for forensic identification of an individual with pathological changes leading to an abnormal gait . Some authors reported that angle is bigger in female Krogman(55,Ref.7). Some authors reported that angle is bigger in males (Henry gray,Ref.3), , RumaPurkait (1996,Ref.11,12); Henry Hollinshead (1966,Ref.5,6) with $126^{0}$ average. , W.T. Hamilton (1976,Ref.4), Gray's text book of Anatomy gives $125^{\circ}$ average, Tanerziylan (2002,Ref.14). The results of neck shaft angle of left femur were generally shown to have greater value, but they were not significantly greater than the corresponding dimensions of right femur (Tanerziylan 2002, Ref.14).

Transverse diameter of head of femur varies from a minimum $28 \mathrm{~mm}$ to maximum $44 \mathrm{~mm}$ with a mean value of $37.86 \mathrm{~mm}$ (table 2). When compared to the range of known sex, 22 femora out of 50 identified as belonging to male and 28 to female (table 5). Transverse diameter of head of femur has been reported earlier. (RumaPurkait 1996,Ref.10). This is not in correlation with the present observation. In the present study (table 3). TanerZiylan (2002,Ref.14) reported that there is no significant difference between Rt and Lt femora $(\mathrm{Rt}=44.7, \mathrm{Lt}=44.3)$. 
Thee is enormous sexual difference in male and female head of femur, the results are of great applied and practical value in referred specimen in medicolegal field (RumaPurkait 1996,Ref.10). In male femur, mean transverse diameter is $86.29 \mathrm{~mm}$ and in female femur, mean transverse diameter is $74.45 \mathrm{~mm}$. this study of diameter of head of femur independently could be used for determining the sex of head of femur with high significant results.

Anteroposterior diameter of femoral shaft, in the present study we had taken measurements of femoral shaft at three different sites, Upper-just below the lesser trochanter, Middle - approximately at the middle of shaft, ie. Highest elevation of lineaaspera. It measures the distance between anterior and posterior surfaces of the bone. Lower - approximately $4 \mathrm{~cm}$ above the cartilaginous margin of condyles taken in mid sagittal plane. Upper anteroposterior diameter of femur ranges from minimum of $22 \mathrm{~mm}$ to maximum of $32 \mathrm{~mm}$ with a mean value of $26.56 \mathrm{~mm}$. Middle anteroposterior diameter of femur varies from minimum of $22 \mathrm{~mm}$ to maximum of $30 \mathrm{~mm}$ with a mean value of $26.38 \mathrm{~mm}$. Lower anteroposterior diameter of femur ranges from minimum of $24 \mathrm{~mm}$ to maximum of $35 \mathrm{~mm}$ with a mean value of $28.50 \mathrm{~mm}$ (table 5). When this is compared to the range of known sex 47 out of 50 femora could be identified as belonging to male and 5 to female by using middle APD. 50 out of 50 could be identified as belonging to male only by using lower APD (table 5). Antero posterior diameter of femoral shaft has been reported earlier (Rumapurkait 1996,Ref.10). This is not in correlation with the present observation. . Studies by Steyn and Iscan(Ref.13) reveal that all dimensions of femur were larger in males than in females, but determination of sex of an individual from a single femur was a more difficult task (TanerZiylan 2002,Ref.14). The shaft of femur is so shaped that it varies at mid-level and at subtrochanteric level. Hence several transverse and sagittal diameters are useful (Krogman 55,Ref.7).The values of three parameters namely, Vertical diameter of head, Neck-shaft angle and Transverse diameter of head in the present study shows. 75$80 \%$ percentage of accuracy of determining the sex of femur when compared to other parameters in this study. Femora are categorized in to 1.Hyperplatymeric,2. Platymeric (flattened),3. Eurymeric (moderate) ,4. Stenomeric (rounded) groupsIn the present study 50 femora are categorized into1. Obelongs Hyperplatymeric,2.6belongs to Platymeric,3.30 belongs to Eurymeric, 4.14 belongs to Stenomeric

Upper (Sagittal) Anteroposterior Diameter of shaft

Platymeric Index: - -

Upper Transverse Diameter of Shaft

This study is to evaluate the subtrochanteric diameters (Anteroposterior and Transverse) in males and females and it is observed that more than 50 percent femora belong to "Eurymeric" group.

Every parameter independent of other contributes certain percentage of certainty to decide the sex of unknown femur. Therefore it is clear that based on no single parameter, sex of femur can be decided. All the parameters have to be considered together for this purpose.

\section{Summary And Conslusion}

50 dry human femora of unknown sex were collected from different medical institution and Anthropology department of S. V. Universit, Tirupati. By eliminating pathologicaly misfit femora, 50 femora in good condition were selected. Each femur was carefully measured for 6 parameters which are already described in materials and methods. The measurements were statistically analyzed and tabulated.

For each femur accurate measurements are taken for 6 parameters namely:

1. Maximum length of femur

2. Vertical diameter of head

3. Epicondylar breadth

4. Neck-shaft angle

5. Transverse diameter of head

6. AP diameter of shaft - Upper,Middle,Lower

The measurements were compared to the values available in reference material. Every parameters is independent of others and contribute certain percentage of certainty to decide the sex of unknown femur. Therefore it is clear that based on no single parameter, sex of femur can be decided. All the parameters have to be considered together for this purpose.The present study reveals that femora of unknown gender can be sexed to the extend of $75-80 \%$ by three parameters namely, Vertical diameter of head, Neck-shaft angle and Transverse diameter of head.Every parameters is independent of others and contribute certain percentage of certainty to decide the sex of unknown femur. Therefore it is clear that based on no single parameter, sex of femur can be decided. All the parameters have to be considered together for this purpose.The present study reveals that femora of unknown gender can be sexed to the extend of $75-80 \%$ by three parameters namely, Vertical diameter of head, Neck-shaft angle and Transverse diameter of head. 
Table -1 Anthropometric data of different parameters of human femora ( $\mathrm{mm}$ )
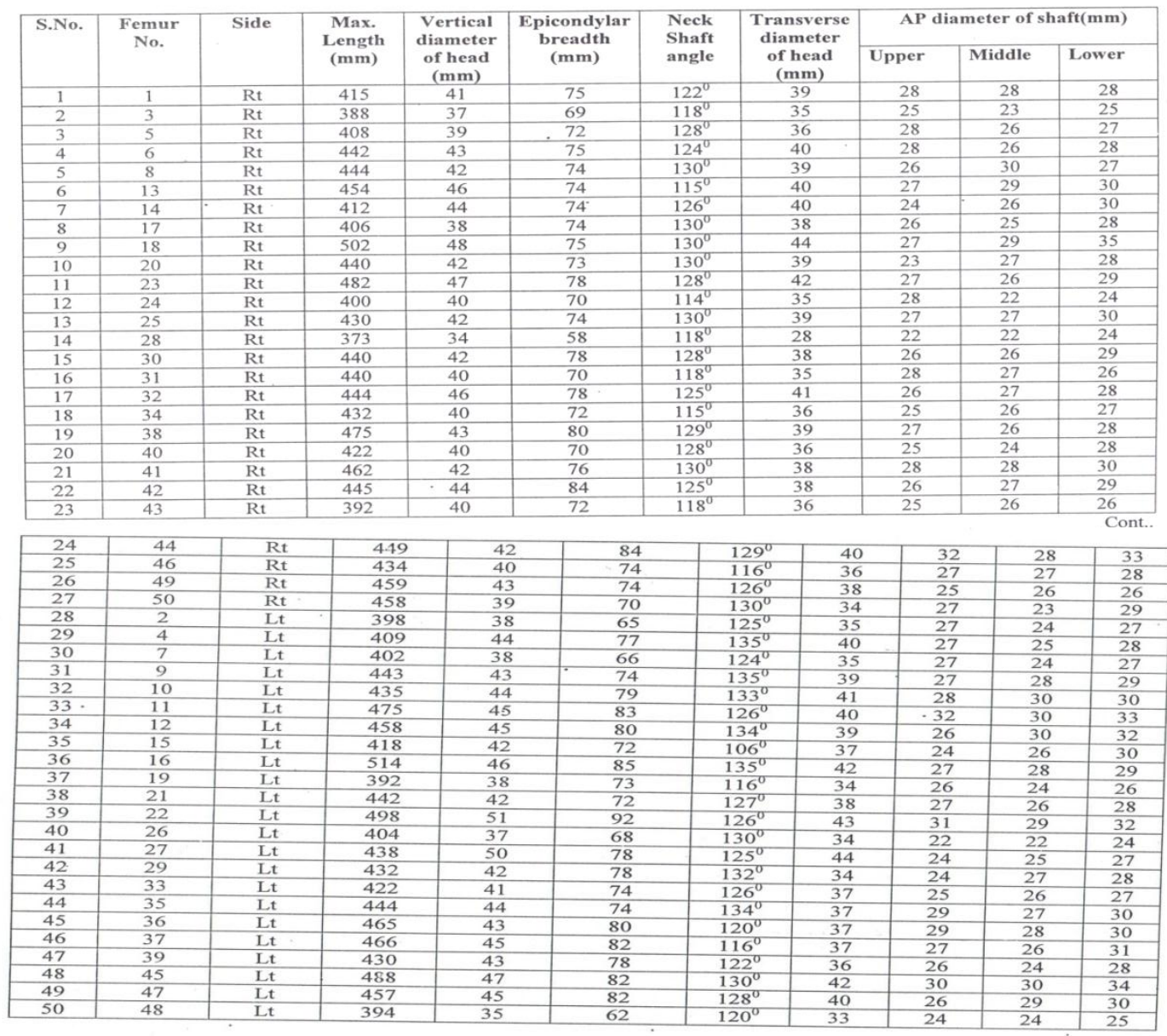

Table:2 Descriptive Statistics

\begin{tabular}{|c|c|c|c|c|c|c|}
\hline Name of the variable & $\mathrm{N}$ & Minimum & Maximum & Mean & Std. Deviation & Variance \\
\hline Maximum Length & 50 & 373.00 & 514.00 & 437.44 & 31.44 & 988.17 \\
\hline $\begin{array}{l}\text { Vertical Diameter of } \\
\text { Head }\end{array}$ & 50 & 34.00 & 51.00 & 42.24 & 3.53 & 12.43 \\
\hline Epicondylar Breadth & 50 & 58.00 & 92.00 & 75.06 & 6.06 & 36.71 \\
\hline Neck-shaft Angle & 50 & 106.00 & 135.00 & 125.30 & 6.50 & 42.30 \\
\hline $\begin{array}{l}\text { Transverse Diameter of } \\
\text { Head }\end{array}$ & 50 & 28.00 & 44.00 & 37.86 & 3.06 & 9.39 \\
\hline $\begin{array}{c}\text { AP Diameter of Shaft } \\
\text { UPPER }\end{array}$ & 50 & 22.00 & 32.00 & 26.56 & 2.14 & 4.58 \\
\hline MIDDLE & 50 & 22.00 & 30.00 & 26.38 & 2.18 & 4.77 \\
\hline LOWER & 50 & 24.00 & 35.00 & 28.50 & 2.45 & 6.01 \\
\hline Valid N (listwise) & 50 & & & & & \\
\hline
\end{tabular}


Table:3 Group Statistics

\begin{tabular}{|l|c|c|c|c|c|}
\hline $\begin{array}{c}\text { Name of the } \\
\text { variable }\end{array}$ & SIDE & N & Mean & Std. Deviation & Std. Error Mean \\
\hline Maximum Length & $\mathrm{Rt}$ & 27 & 435.11 & 29.680 & 5.712 \\
Vertical Diameter & $\mathrm{Lt}$ & 23 & 440.17 & 33.842 & 7.057 \\
& $\mathrm{Rt}$ & 27 & 41.63 & 3.090 & 0.595 \\
Epicondylar Breadth & $\mathrm{Lt}$ & 23 & 42.96 & 3.925 & 0.818 \\
& $\mathrm{Rt}$ & 27 & 73.96 & 4.996 & 0.961 \\
Neck-shaft Angle & $\mathrm{Lt}$ & 23 & 76.35 & 7.004 & 1.460 \\
Transverse Diameter & $\mathrm{Rt}$ & 27. & 124.44 & 5.700 & 1.097 \\
& $\mathrm{Lt}$ & 23 & 126.30 & 7.339 & 1.530 \\
AP Diameter of Shaft & $\mathrm{Rt}$ & 27 & 37.74 & 3.058 & 0.589 \\
UPPER & $\mathrm{Lt}$ & 23 & 38.00 & 3.133 & 0.653 \\
& $\mathrm{Rt}$ & 27 & 26.41 & 1.927 & 0.370 \\
MIDDLE & $\mathrm{Lt}$ & 23 & 26.74 & 2.397 & 0.500 \\
& $\mathrm{Lt}$ & 27 & 26.19 & 2.020 & 0.389 \\
LOWER & $\mathrm{Rt}$ & 23 & 26.60 & 2.388 & 0.498 \\
& $\mathrm{Lt}$ & 23 & 28.15 & 2.391 & 0.461 \\
\end{tabular}

No significant difference in femurs between right and left side

\begin{tabular}{|c|c|c|c|c|c|c|c|}
\hline \multirow[t]{2}{*}{ Variables } & \multicolumn{4}{|c|}{ Mean values of past studies references } & \multicolumn{3}{|c|}{$\begin{array}{c}\text { Mean Values (T) Present } \\
\text { Study }\end{array}$} \\
\hline & & & Mean & S.D & & Mean & S.D \\
\hline \multirow[t]{4}{*}{ 1. Maximum Length } & 1. Krogman & & $\begin{array}{l}477.34 \\
439.10\end{array}$ & $\begin{array}{l}28.37 \\
24.55\end{array}$ & & & \\
\hline & 2. Leelavathy. $\mathrm{N}$ & $M=1$ & 443.30 & 15.40 & & $\mathrm{R}=435.11$ & 29.68 \\
\hline & & $F=I$ & $\begin{array}{l}443.20 \\
404.20\end{array}$ & $\begin{array}{l}14.60 \\
30.60\end{array}$ & & $\mathrm{~L}=440.17$ & 33.84 \\
\hline & $x_{0}+2$ & & 401.80 & 33.10 & . & & \\
\hline \multirow{2}{*}{$\begin{array}{l}\text { 2. Vertical Diameter } \\
\text { of head }\end{array}$} & 1 Krogman & $\begin{array}{l}\mathrm{M}= \\
\mathrm{F}=\end{array}$ & $\begin{array}{l}47.17 \\
41.52\end{array}$ & $\begin{array}{l}2.75 \\
2.12\end{array}$ & & $R=41.63$ & 3.09 \\
\hline & 2 Ruma purkait & $\begin{array}{l}\mathrm{M}= \\
\mathrm{F}=\end{array}$ & $\begin{array}{l}74.23 \\
63.50 \\
\end{array}$ & $\begin{array}{l}4.90 \\
4.79\end{array}$ & & $L=42.96$ & 3.92 \\
\hline 3. Epicondylar & 1 Ruma Purkait & $\mathrm{M}=$ & $\begin{array}{l}78.04 \\
67.13\end{array}$ & $\begin{array}{l}4.48 \\
3.92\end{array}$ & & $\begin{array}{l}\mathrm{R}=73.96 \\
\mathrm{~L}=76.35\end{array}$ & 5.00 \\
\hline \multirow[t]{2}{*}{ 4. Neck shaft angle } & 1.W.J. Hamilton & $127^{\circ} \mathrm{C}$ & $\begin{array}{l}67.13 \\
110-140^{\circ}\end{array}$ & & & $\begin{array}{l}\mathrm{L}=76.35 \\
\mathrm{R}=122.44^{\circ} \\
\mathrm{L}=126.30^{\circ}\end{array}$ & $\begin{array}{l}7.00 \\
5.70\end{array}$ \\
\hline & $\begin{array}{l}\text { 2.Pick.JW et al - } \\
\text { 1. Ruma purkait }\end{array}$ & $\frac{126^{\circ}}{\mathrm{M}=}$ & $\frac{104-147^{0}}{44.28}$ & 2.48 & & $\begin{array}{l}\mathrm{L}=126.30^{\circ} \\
\mathrm{R}=37.74\end{array}$ & $\frac{7.33}{3.05}$ \\
\hline $\begin{array}{l}\text { 5. Transverse } \\
\text { diameter of head }\end{array}$ & & $\mathrm{F}=$ & 38.39 & 2.14 & & $\mathrm{~L}=38.00$ & 3.13 \\
\hline \multirow{4}{*}{$\begin{array}{l}\text { 6. AP diameter of } \\
\text { shaft }\end{array}$} & 1.Ruma purkait & $\mathbf{M}=$ & 27.95 & 2.12 & Upper & $R=26.40$ & 1.93 \\
\hline & & $F=$ & 23.38 & 1.79 & & $\mathrm{~L}=26.73$ & 2.40 \\
\hline & & & & & Middle & $\begin{array}{l}\mathrm{R}=26.20 \\
\mathrm{~L}=26.61\end{array}$ & $\begin{array}{l}2.02 \\
2.40\end{array}$ \\
\hline & & & & & Lower & $\begin{array}{l}\mathrm{R}=28.14 \\
\mathrm{~L}=28.91\end{array}$ & $\begin{array}{l}2.40 \\
2.50\end{array}$ \\
\hline
\end{tabular}

Table 5: Sexing of "Femur" by Individual Parameters

\begin{tabular}{|l|l|c|c|c|}
\hline S.No & \multicolumn{1}{|c|}{ Parameters } & Males & Females & N \\
\hline 1 & Maximum Length & 42 & 08 & 50 \\
2 & Vertical Diameter & 23 & 27 & 50 \\
3 & Epicondylar Breadth & 46 & 04 & 50 \\
4 & Neck-Shaft angle & 24 & 26 & 50 \\
5 & Transverse diameter & 22 & 28 & 50 \\
& Upper & 47 & 03 & \\
& Middle & 45 & 05 & 50 \\
& Lower & 50 & 00 & \\
\hline
\end{tabular}

\section{References}

[1]. 1.Alan M. W. Porter1995 Analysis of measurements taken from adult femora of British population.

[2]. Asala . S.A. et al 2004 Discriminant function sexing of fragmentary femur of South African blacks, vol 145, issue 1. p. 25-29

[3]. Bannister Lawrence. H 1995 Gray's Text Book of Anatomy, 38 ${ }^{\text {th }}$ Edition P. 678-684

[4]. Hamilton W.J1976 Text book of human anatomy, $2^{\text {nd }}$ Edition P. 117-120

[5]. Henry hollinsead. W1966 Text book of Anatomy, Indian edition (Hoeber medical division) P. 404-407 6.Henry Hollinshead. W 1958 Anatomy for surgeons, Vol-3 P. 654-657

[6]. Krogman, W.M and Iscan, M.Y 1986 Human skeleton in forensic medicine $2^{\text {nd }}$ edition.

[7]. Leelavathy, et al 2000 Sexing of the femora, Journal of the Anatomical Society of India, Vol -49, no. 1, P. 17-20.

[8]. Mall G, Graw M et al 2000 Determination of sex from femora, Forensic science International, Vol - 113, No.1 P. 315-321

[9]. Purkait. R1996 Sex determination from femur: Standardization of measurement using fovea as land mark. J. Hum, Ecol, Vol-7, issue 1, P. 25-28.

[10]. Ruma Purkait2004 A study of sexual variation in Indian femur, Vol 146, issue 1, p:25-33

[11]. Ruma Purkait2002 Review of Anthropometric techniques, Man in India, Vol -82 (issue 1 \& 2) P. 185-191.13Steyn M. Iscan M1997 Sex determination from the femur and tibia in South African Whites, Forensic Science International, Vol - 90; P. 111-119.

[12]. Taner Ziylan2002 An Analysis of Anatolian Human femur Anthropomet6ry, Turkey Journal of Medical Sciences, Vol - 32, P. 231235 